\title{
Effective Framework of Pedagogy
}

\author{
Using the Plan-Do-Check-Act Improvement Cycle
}

\author{
Tallat Naz ${ }^{1}$, Momeen $\mathrm{Khan}^{2}$, Khalid Mahmood ${ }^{3}$ \\ Department of Computer Science, IIC University of Technology \\ Phnom Penh, Cambodia
}

\begin{abstract}
Learning paths drive learners to proficiency by using a selected sequence of training activities under time constraints. Therefore, learners can regulate learning and give feedback for pedagogy improvements. Studying learning path evaluation provides a useful conceptual reference to enhance pedagogically. This paper proposes an approach based on the Plan-Do-Check-Act improvement cycle to systematically evaluate learning paths in learning management systems. The framework is a valuable resource that consolidates existing practices in learning management evaluation. Our approach integrates learning styles, learning profile, along with cognitive activities. The proposed framework was compared with current learning path methods. Results were competitive compared with related works.
\end{abstract}

Keywords-Learning management system; learning styles; learning path; Plan-Do-Check-Act (PDCA)

\section{INTRODUCTION}

A learning management system (LMS) provides functions of course creation tools, tracking, assessment, collaboration, and reporting to learners and administrators. An LMS provides content managers with the tools to create learning paths for specific course outcome. A learning path is a guided set of educational activities that aim to increase learner proficiency; thus, it is considered an organizational asset. A learning path should consider the current learner skillset, the required job skills, and the future learner skillset to fulfill his career goals.

A useful LMS should provide facilities to create and track the learning paths of prospective employees. Therefore, it aligns job skillset with resources; consequently, the organization LMS value is increased. However, building a learning path without taking personal preferences, cognitive activities, and learning style into consideration could lead to improper resources required to carry out the LMS project tasks. Without considering the overall value of the learning path to an organization, the learning path assessments remain provisional. Therefore, a non-achieved course or a seminar outcome could lead to organization goal failure.

Although there are many works on learning path creation and optimization [1]-[4], little work exists on learning path evaluation from the viewpoint of teachers. An assessed learning item of a learning path provides little feedback on current courses content or course items sequence. Therefore, the problem learning path evaluation is seen as a personal activity of learners, leaving the teacher assessment out of scope.

In practice, a learning path evaluation process should consider multidimensional data including learning profile, preferences, and behavior actions. A useful learning profile helps learner strive to be inquirers, knowledgeable, communicators and reflective. Learner preferences are based on their expected learning targets, timeframes, and budget constraints. Behavior actions include history and $\log$ files, learner recommendation, and learner usability records of an LMS.

We claim that enhancing pedagogy is affected by Porter's five forces [5] in the context of e-learning systems. The competitive rivalry of other active learning paths; the threat of adding extra, unrelated, or improper learning items sequences; the threat of substituting new learning seminars; and the bargaining power between learner and the instructor.

This paper applies Deming's plan-do-check-act (PDCA) cycle [6] (as shown in Fig. 1) to improve and evaluate the learning paths of LMSs. At the planning phase, the course outcomes are linked to a set of processes toward creating new or improved course content. Then the set of activities in the planning phase is executed in the "do" phase. The "check" phase evaluates the learning path based on available data. Consequently, the "act" phase fixes issues and recommends actions that need human involvement. The PDCA iterates until satisfaction determined by the evaluator. Table I. shows a list of the PDCA actions under PDCA phase. In each phase of the PDCA, a set of actions is proposed that systematically combine learning profile, the existing log file of LMS, and learning styles. Therefore, the statistics of learners and teachers are combined.

The paper is structured as follows. Section 2 summarizes related work. Section 3 explains the proposed model, while Section 4 evaluates the proposed model. Section 5 provides conclusions and future research. 


\section{Learning Path Evaluation: Plan-Do-Check-Act Cycle}

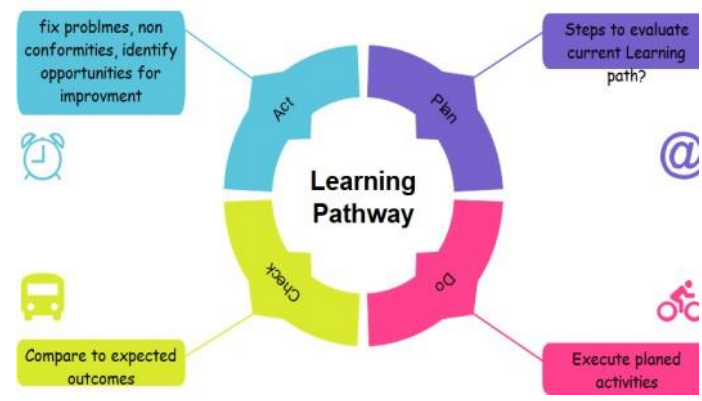

Fig. 1. Learning Path Plan-do-Check-Act Cycle.

TABLE I. The PDCA Stages in the Learning Path Evaluation PROCESS

\begin{tabular}{|l|l|}
\hline Phase & Action \\
\hline Plan & $\begin{array}{l}\text { develop a learner personnel profile identify } \\
\text { the learning style } \\
\text { apply cognitive activities } \\
\text { process LMS repository datasets acquire } \\
\text { organization assets }\end{array}$ \\
\hline Do & the previous step is enacted \\
\hline Act & $\begin{array}{l}\text { course objectives coverage sequencing of } \\
\text { learning activities course learning and } \\
\text { practice time relationship or synthesis } \\
\text { within learning provided by other sources. }\end{array}$ \\
\hline $\begin{array}{l}\text { extend or improve course objectives alter } \\
\text { sequencing of learning activities modify } \\
\text { required practice time } \\
\text { address learning of knowledge within the tasks or activities of } \\
\text { learning path identify gaps in the learning process compared } \\
\text { with other sources. }\end{array}$ \\
\hline
\end{tabular}

\section{RELATED WORK}

\section{A. Learning Management System Evaluation}

In the market, there are more than 300 active LMSs that provide basic features like content options, course creation tools, assessments, collaboration, reporting, and skill tracking. Many LMSs provide mobile learning, certification management, gamification, and social learning. One major feature of an LMS is the Shareable Content Object Reference Model (SCORM). SCORM defines a way of constructing training content so it can be shared with other SCORM compliant systems. LMSs can be in three main categories: content preparation systems like Moodle and Blackboard; corporate training systems like Litmos, and Zoho recruit; and school management systems like Edmodo, and Schoology. A useful LMS should be scalable, user-friendly with simple reporting features. The progress tracking and evaluation of learning goals ensure effective pedagogy.

There are many approaches to evaluate LMSs. Gartner uses a data-driven approach known as the magic quadrant. The quadrant has two dimensions the capability and value. The capability focuses on an LMS capability such as functionality and system integration while the value provides dimensions of satisfaction and market price [7][8]. The quadrant dimension identifies learners, masters, pacesetters, and contenders.

The adoption of an LMS has been further studied [9] to identify technology and pedagogy effect on the learning process. The study identified a lack of development in LMS usage and pedagogy. The predictors of behavioral intention to use an LMS are identified as perceived usefulness, perceived ease of use, enjoyment, subjective norm, satisfaction, and interactivity and control with the validated structural model [10]. Author in [11] identified that tracking, deficiency of audit trail, and insufficient reporting are the main gaps in current LMS systems.

The adoption of an LMS depends on technology, system usefulness, and organizational constraints. Technology issues such perceived use and usefulness are the main factors in an LMS adoption [12]. However one of the most widely used models, the technology acceptance model (TAM) and its variants are problematic with conflicting results [12]. A unified theory of acceptance and use of technology (UTAUT) model was proposed to handle the limitation of a single technology model [13].

Other approaches try to evaluate an LMS system from the utility function. The reference [14] handled the satisfaction and usability factors of LMS using the Analytical Hierarchy Process (AHP) approach to determine satisfaction factors (accuracy, timeless, ease of use and format). They found that the design of an LMS interface will enrich the effectiveness of pedagogy. They identified interface problems with their root cause using the ISO 9241-11 model [15]. Other approaches evaluate the usability of software, in general, using software comments [16], [17]. Teachers believe that an LMS is useful in communication and improving learning while students barely believe that an LMS usage improves teaching [18]. Therefore, organizational support is needed to provide pedagogy. Reported results support the hypotheses that organizational support plays a primary role in enhancing the faculty's LMS self-efficacy and technical support [19].

\section{B. Learning Styles}

Learning styles provide common ways of learning. Some people prefer using pictures while others prefer to use music. VARK is one of the leading models of learning styles that refers to the learning styles: visual, auditory, reading/writing preference, and kinesthetic [20]. A right LMS should provide cognitive and self-directing skills [4]. Personality evaluation could be used for guiding the students according to their preferences [21]. There is a direct relationship between learning styles and personality traits [21]. The reference [22] proposed a neural network model to detect learning styles. The reference [23] focused on recommending learning contents with an adaptive user interface. The course interface was changed using the Felder-Silverman Learning Style Model (FSLSM) model and generic adaptive rules.

\section{Learning Paths}

One possible way to evaluate the learning path is by using a checklist guide. System reports about collected data of learner activities of keystrokes and mouse clicks is another approach. However, other approaches are based on previous knowledge 
and log file of online activities [1]; therefore, the seminar taken adequately by learner interacts with individual preference [1]. The reference [2] proposed a genetic algorithm to sequence learning path based on learner preferences. Learning analytics provides tools for collecting analyzing data about learners to optimize learning. The learning processes could be understood and managed using learning analytics approach [3]. Therefore, learner preferred learning modes and modality preferences influence their learning and capabilities. The preferred learning modes should be matched with an appropriate learning path.

\section{PROPOSED FRAMEWORK}

Learners can self-regulate their learning based on cognitive and behavioral dimensions. However, learners are influenced by external factors of seminar content style (teacher style) compared to his (internal) learning style. Therefore, the proposed model takes into consideration the learner style and his profile.

Fig. 2 depicts the proposed model. The model is composed of two significant steps the "plan-do" and "check- act" of the learner path cycle. The "develop profile" process captures information from the LMS repository including previous courses taken, learner actions, and the LMS user behavior. The process also is subject to organizational process assets that could be part of the LMS. Organizational process assets include policies, procedures, learning process, lesson learned, and other knowledge that is deemed appropriate for the organization such as an HR system.

Therefore, taking the learning outcome as the critical part of the learning path evaluation, then we express the learning path effectiveness as shown in equation (1).

Effectivness $=\frac{\sum \text { weight }_{i} \cdot \text { Acc }_{i}}{\sum \text { weight }_{i}}$

The second process, "identify learning style", is crucial to pedagogy and an active learning path. Learners should be comfortable with learning contents that matches with their cognitive abilities. In this process, using available learning styles such as VARK and FSLSM, the leaner should be categorized to his preferred content. For example, a visual learner style implicates the need for visual course contents. Visual learning retains twice as much information as those in the auditory condition [24]. The identification of a leaner style is affected by factors such as organization, cognitive abilities, and technical constraints [25]. Several lite tests should be carried out to identify the learner style.

The primary critical step of the proposed framework is the "evaluate learning path" shown in the second phase of the framework. The process has several sub-processes as stated in Fig. 3(a) to Fig. 3(d). Table II summarizes these subprocesses and the "act" that we propose to use.

Where weight $_{i}$ is the weight of the outcome $i, A c c_{i}$ is the accuracy of a completed outcome $i$. The weight of an outcome is calculated based on the outcome importance or time needed to accomplish the outcome. A teacher should score each outcome value to quantify pedagogy. However, the terms in equation (1) depends on quantifying the prescriptions and actions in Table III which is outside the scope of this paper.

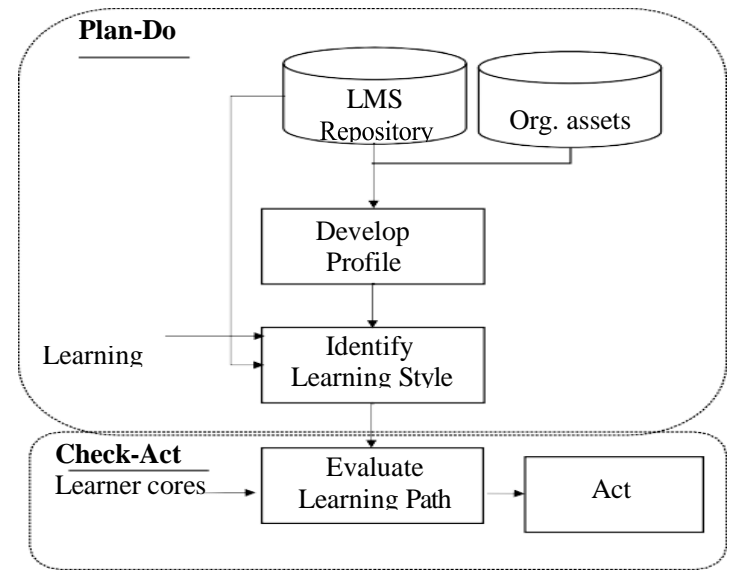

Fig. 2. Proposed Model.

TABLE II. LEARning PATH Evaluation (THE "CheCK-ACT" OF THE PDCA)

\begin{tabular}{|c|c|c|}
\hline Figure & Description & Action \\
\hline 3(a) & $\begin{array}{l}\text { Was the course expected } \\
\text { outcomes covered in the } \\
\text { learning path? }\end{array}$ & $\begin{array}{l}\text { If the average learners' score for } \\
\text { the learning path is less than } \\
50 \% \text {, then prompt an immediate } \\
\text { update to course outcomes or } \\
\text { contents. } \\
\text { Start a process to address gained } \\
\text { learning knowledge. }\end{array}$ \\
\hline 3(b) & $\begin{array}{l}\text { Check learning path } \\
\text { sequence of activities } \\
\text { (curriculum)? }\end{array}$ & $\begin{array}{l}\text { If average learners score of a } \\
\text { subset of learning path is below } \\
50 \% \text {, then consider better } \\
\text { sequencing or improving course } \\
\text { content. }\end{array}$ \\
\hline $3(c)$ & $\begin{array}{l}\text { Check the alignment } \\
\text { between course } \\
\text { contents and allotted } \\
\text { time? }\end{array}$ & $\begin{array}{l}\text { If the average number of learners } \\
\text { fails to complete the course item } \\
\text { in allotted time, then consider } \\
\text { either extending time or splitting } \\
\text { Course item. }\end{array}$ \\
\hline $3(d)$ & $\begin{array}{l}\text { Does the learning path } \\
\text { do better than other } \\
\text { competitors? }\end{array}$ & $\begin{array}{l}\text { If the number of enrollments in } \\
\text { the current learning path of an } \\
\text { LMS is less than a competitor } \\
\text { LMS, then consider a revision of } \\
\text { sequence, content, price, } \\
\text { Enrollment process and course } \\
\text { features. }\end{array}$ \\
\hline
\end{tabular}

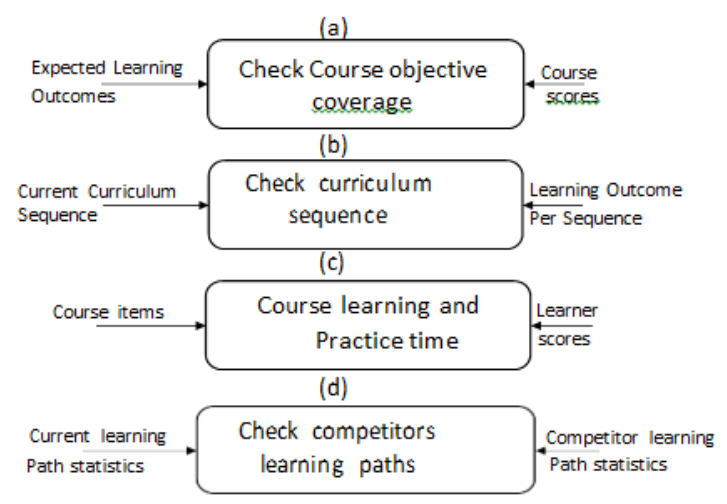

Fig. 3. Evaluating Learning Path Process (Check-Act). 


\section{EVALUATION}

Although many works have been adopted to evaluate a learning path, most works target learning path design. To our knowledge, no complete learning path framework quantify learning path from learner and teacher perspectives. The proposed framework is an overarching approach intended to measure the learning path effectiveness from the learner and the organization (teacher) point view.

We carry out a comparison against the following list of learning path evaluation features that are either extracted from the literature review or suggested by this paper. The suggested criteria are as follows:

1) Agility: The ability to be flexible and able to deal with unseen changes in technology, environment, and pedagogy.

2) Overall performance: The ability to measure the overall performance of a specific learning path.

3) Identify course content gaps: The framework should be able to detect if learning material should be changed

4) Learner profile: An overall framework should beable to take into consideration the learner profile including the cognitive and learning styles.

Table III shows the comparison of our approach and a list of selected works from the literature. The $\square$ indicates that the criterion is fully available while $₫$ means a non-applicable criterion.

From the table, we deduce that the proposed model and selected works are agile, since they are not linked to specific learning management platform. All the studied evaluation methods do not provide the ability to evaluate the learning path from the organization and learner perspectives. The works [1] and [3] did not provide feedback on learning course items or feedback back to expected learning outcomes. The lowest performance was in LMS reports that only use log files of learner actions. The proposed approach reported the highest performance due to its abstractness and richness of extra knowledge extracted from learning styles, preferences, and cognitive activities.

The proposed framework was evaluated experimentally by expert judgment. Teachers liked the idea, but they were looking for a real-life system while learners were happy with the feature of learning style detection. Moreover, one organization that adopts an LMS likes the idea of linking organization assets with the LMS learning path.

TABLE III. COMPARISON OF OUR APPROACH AND RELATED APPROACHES

\begin{tabular}{|c|c|c|c|c|c|c|}
\hline Criterion & Our approach & Checklist & $\begin{array}{l}\text { LMS } \\
\text { reports }\end{array}$ & {$[1]$} & [2] & [3] \\
\hline A & $\nabla$ & 凶 & $\nabla$ & $\square$ & $\nabla$ & $\nabla$ \\
\hline B & $\nabla$ & $凶$ & 凶 & 凶 & 凶 & 凶 \\
\hline $\mathrm{C}$ & $\nabla$ & $\nabla$ & 凶 & 凶 & $\square$ & 凶 \\
\hline D & $\nabla$ & $\nabla$ & 凶 & $\nabla$ & $\nabla$ & $\nabla$ \\
\hline
\end{tabular}

\section{DISCUSSION}

This study extends previous work on learning path evaluation by providing a theoretical framework that specifies the unidirectional feedback between learners and teachers. It also offers several important implications for research and practice, and thus should help in the design, evaluation and widespread adoption in LMSs.

Despite the significant contribution of the research findings, this study involved limitations that should be considered when interpreting the results. First, the features of influencing learning styles evaluations are primarily identified based on a limited number of literature reviews from 20102018. This limitation may restrain the generalizability of the findings, and hence, future researchers should interpret the current findings with caution. Second, the proposed approach has not been implemented in an LMS. Therefore, results probably only reflect the general concept of a learning path evaluation. Future work should consider the application of machine learning approaches to analyze and categorize collected data, before proceeding to implementation.

\section{CONCLUSIONS}

This paper proposes a learning path framework that can measure the effectiveness of a learning path. The proposed model evaluates the learning path from the viewpoint of learners, teachers, and organization. The model is based on learner style, profile, and cognitive activities. The evaluation was carried out by comparison of the proposed model with a list of related works. Results show that the framework is deemed useful in the context of state of the art LMSs. In the future, we plan to implement the framework in an open source LMS such as Moodle.

\section{REFERENCE}

[1] T. Lerche and E. Kiel, "Predicting student achievement in learning management systems by $\log$ data analysis," Comput. Human Behav., vol. 89, pp. 367-372, 2018.

[2] P. Dwivedi, V. Kant, and K. K. Bharadwaj, "Learning path recommendation based on modified variable length genetic algorithm," Educ. Inf. Technol., vol. 23, no. 2, pp. 819-836, 2018.

[3] C. Schumacher and D. Ifenthaler, "Features students really expect from learning analytics," Comput. Human Behav., vol. 78, pp. 397-407, 2018.

[4] M. Rani, K. V. Srivastava, and O. P. Vyas, "An ontological learning management system,” Comput. Appl. Eng. Educ., vol. 24, no. 5, pp. 706722, 2016.

[5] M. E. Porter, "The five competitive forces that shape strategy,"Harv. Bus. Rev., vol. 86, no. 1, pp. 25-40, 2008.

[6] R. D. Moen and C. L. Norman, "Circling back: Clearing up myths about the Deming cycle and seeing how it keeps evolving," Qual. Prog., vol. 43, no. 11, p. 22, 2010.

[7] Gartner® Inc, "FrontRunners Methodology," 2018. [Online]. Available: https://www.saimgs.com/imglib/other_pages/FrontRunners/Meth odologyOverview.pdf. [Accessed: 28-Feb-2019].

[8] Gartner, "Magic Quadrant for Business Intelligence and Analytics Platforms, Retrived on 15 October, 2017 from https://www.gartner.com/ doc/reprints?id=1-3TYE0CD\&ct=170221\&st=sb," 2017.

[9] J. Sinclair and A.-M. Aho, "Experts on super innovators: understanding staff adoption of learning management systems," High. Educ. Res. Dev., vol. 37, no. 1, pp. 158-172, 2018. 
[10] D. Findik-Colcskunçay, N. Alkilcs, and S. Özkan-Yildirim, "A Structural Model for Students' Adoption of Learning Management Systems: An Empirical Investigation in the Higher Education Context," J. Educ. Technol. Soc., vol. 21, no. 2, pp. 13-27, 2018.

[11] "Functionality Gaps in the Design of Learning Management Systems," Int. J. Adv. Comput. Sci. Appl.

[12] R. R., "Why some teachers easily learn to use a new virtual learning environment: A technology acceptance perspective," Interact. Learn. Environ., vol. 24, p. 539, 2014.

[13] V. Venkatesh, J. Y. L. Thong, and X. Xu, "Consumer acceptance and use of information technology: extending the unified theory of acceptance and use of technology," MIS Q., vol. 36, no. 1, pp. 157- 178, 2012.

[14] Y. Tjong, L. Sugandi, A. Nurshafita, Y. Magdalena, C. Evelyn, and N. S. Yosieto, "User Satisfaction Factors on Learning Management Systems Usage," in International Conference on Information Management and Technology (ICIMTech 2018), 2018, pp. 11-14.

[15] N. Phongphaew and A. Jiamsanguanwong, "Usability evaluation on learning management system," in International Conference on Applied Human Factors and Ergonomics, 2017, pp. 39-48.

[16] I. Atoum, "A Novel Framework for Measuring Software Quality- in-use based on Semantic Similarity and Sentiment Analysis of Software Reviews,” J. King Saud Univ. - Comput. Inf. Sci., p. , 2018.

[17] I. Atoum and C. H. Bong, "A Framework to Predict Software 'Quality in Use' from Software Reviews," in Proceedings of the First International Conference on Advanced Data and Information Engineering (DaEng2013), vol. 285, J. Herawan, Tutut and Deris, Mustafa Mat and Abawajy, Ed. Kuala Lumpur: Springer Science+Buisness Media Singapore, 2014, pp. 429-436.
[18] T. S. D., "Saving time or innovating practice: Investigating perceptions and uses of learning management systems," Comput. Educ., vol. 53, p. 686, 2009.

[19] Y. Zheng, J. Wang, W. Doll, X. Deng, and M. Williams, "The impact of organisational support, technical support, and self- efficacy on faculty perceived benefits of using learning management system," Behav. Inf. Technol., vol. 37, no. 4, pp. 311-319, 2018.

[20] N. D. Fleming, "I'm different; not dumb. Modes of presentation (VARK) in the tertiary classroom," in Research and development in higher education, Proceedings of the 1995 Annual Conference of the Higher Education and Research Development Society of Australasia (HERDSA), HERDSA, 1995, vol. 18, pp. 308-313.

[21] A. Kamal and S. Radhakrishnan, "Individual learning preferences based on personality traits in an E-learning scenario," Educ. Inf. Technol., vol. 24, no. 1, pp. 407-435, 2019.

[22] M. S. Hasibuan, L. E. Nugroho, and P. I. Santosa, "Model detecting learning styles with artificial neural network," J. Technol. Sci. Educ., vol. 9, no. 1, pp. 85-95, 2019.

[23] S. V. Kolekar, R. M. Pai, and M. P. Manohara, "Rule based adaptive user interface for adaptive E-learning system," Educ. Inf. Technol., 2018.

[24] J. Cuevas and B. L. Dawson, "A test of two alternative cognitive processing models: Learning styles and dual coding," Theory Res. Educ., vol. 16, no. 1, pp. 40-64, 2018.

[25] S. Graf, T.-C. Liu, and others, "Identifying learning styles in learning management systems by using indications from students' behaviour," in Eighth IEEE international conference on advanced learning technologies, 2008, pp. 482-486. 